\title{
PROXIMATE COMPOSITION, ANTIOXIDANT ACTIVITIES AND FATTY ACID PROFILING OF SELECTED MUSHROOMS COLLECTED FROM AZAD JAMMU AND KASHMIR
}

\author{
MUHAMMAD SHAHID ${ }^{*}$, HINA FATIMA ${ }^{1}$, FOZIA ANJUM ${ }^{2}$, MUHAMMAD RIAZ $^{*}$, \\ NAHEED AKHTER ${ }^{4}$ and MIAN ANJUM MURTAZA ${ }^{5}$ \\ ${ }^{1}$ Department of Biochemistry, University of Agriculture, Faisalabad (38040) Pakistan \\ ${ }^{2}$ Department of Chemistry, Government College University Faisalabad, \\ Faisalabad (38000) Pakistan \\ ${ }^{3}$ Department of Allied Health Sciences, Faculty of Medical and Health Sciences, \\ University of Sargodha, Sargodha (40100) Pakistan \\ ${ }^{4}$ College of Allied Health Professionals, Faculty of Life Sciences, \\ Government College University Faisalabad, Faisalabad (38000) Pakistan \\ ${ }^{4}$ Institute of Food Science and Nutrition, University of Sargodha, Sargodha (40100) Pakistan
}

\begin{abstract}
Mushrooms can be used in diet as nutraceutical or functional food for promoting and maintaining health quality and health longevity. Mushrooms just like medicinal plants can be utilized in the form of powder or extract as curative agents of several diseases and in providing a healthy diet. In the current study, ten different mushroom species were collected from Azad Jammu and Kashmir. The selected mushrooms were assessed for their nutritional value, biological activities and fatty acid profiling. Before extraction, proximate analysis of all selected mushrooms was performed. Protein, fat, ash and total carbohydrate contents ranged from $10-30 \%, 0.43-8.08 \%, 1.1-9.14 \%, 12.47-92.52 \%$, respectively. Then mushrooms were extracted with three different solvents $n$-hexane, ethyl acetate and methanol for the assessment of their antioxidant potential through different antioxidant assays like total phenolics, total flavonoid contents and DPPH inhibition assay. The order of antioxidant potential in different solvents is methanol $>$ ethyl acetate $>n$-hexane. Quantification of fatty acids by GC/MS analysis revealed that stearic acid, palmitic acid, oleic acid, linolenic acid were present in significant quantity in different mushrooms and unsaturated fatty acids were found abundant over saturated fatty acids in all the selected mushrooms. So the presence of fatty acids in studied samples is one of the main biologically active ingredients from mushrooms. The study concluded that the selected mushrooms from different regions of Azad Jammu and Kashmir are of nutritional importance having significant antioxidant potential and contain several unsaturated fatty acids that contribute to the nutritional value of mushrooms.
\end{abstract}

Keywords: mushroom, nutraceutical, antioxidants, fatty acids

One of the world's biggest challenges is food insecurity that is common in developing countries that have reduced the food production systems resulting in malnutrition. Current food production systems are insufficient due to increasing population growth. Research on making proteins from non-conventional sources as an approach of dietary supplements has improved with the growing global burden for good quality food (1). The modern food technology can also extend a great deal for the production of certain kinds of food from mushrooms and related species (2). Mushrooms contain a momentous quantity of dietary nutraceutical fibers, peptides, proteins, polyunsaturated fatty acids (PUFA), amino acids, minerals, keto acids, antioxidative vitamins and other antioxidants such as polyphenols and tocopherols (3).

Mushrooms are the manifestation of a common saying, "Medicines and foods have a similar origin". Mushrooms can be used as a component of functional foods and are a useful source of medicines. In past decades, Chinese, Mexicans, Greeks, Romans and Egyptians preferred mushrooms only for their cooking characteristics, while their functional and

* Corresponding author: e-mail: (M.R.) riazmlt786@gmail.com, (M.S.) mshahiduaf@yahoo.com 
nutritional values were also recognized (4). Almost 140000 species of mushrooms are present in nature, however, a smaller amount is being extensively used for food and have gained the rank of the business item (5). China was the world's major consumer and producer of mushrooms and yield in 2011 accounted above $75 \%$ of the worldwide supply (6). In China, Yunnan province is rich in wild-grown mushrooms with 880 different species recognized as edible accounting for $80 \%$ of the edible mushrooms identified in China and (7). In Pakistan, fifty-six edible species of mushrooms have been reported including four from Balochistan, three from Sindh, five from Punjab and forty-four from Khyber Pakhtoon Khwah (KPK) and Kashmir (8).

The use of natural antioxidants, particularly the phenolics and flavonoids in foods in addition to preventive and therapeutic medicines, is gaining much recognition because of their health improving efficiency (9). Recent epidemiological studies have shown that the use of natural antioxidants such as mushrooms phenols, flavonoids, and ascorbic acid resulted in decreased frequency of chronic diseases, cancer and cardiovascular diseases. Natural antioxidants are supposed to play a vital role to impede with oxidation process through scavenging of free radicals, neutralizing oxygen species and chelating with metals in biological and food systems. Synthetic antioxidant compounds have been extensively used for enhancing the shelf life of foods and preventing oxidation. However, the addition of synthetic antioxidants in food is dampened owing to their perceived carcinogenic potential (10). Mushrooms are also considered a significant and potent source of phytoconstituents including tocopherols, flavonoids, ascorbic acid, $\beta$-carotene, glycosides, saponins, tannins and alkaloids that differ among species renowned for their pharmaceutical properties $(11,12)$.

In Pakistan, mushrooms cultivation has not been given importance, however, there is favorable environment including a huge quantity of waste material (decaying plant matter, organic disposals of food industries, wood logs) suitable for the production and growth of mushrooms that can be used for preparing functional foods. The present research was planned to study the proximate composition, antioxidant activities and fatty acid profiling of mushrooms collected from Azad Jammu and Kashmir.

\section{MATERIALS AND METHODS}

\section{Sample collection and processing}

Selected mushroom samples were collected from Muzaffarabad and Neelum Valley districts of Azad Jammu and Kashmir (Table 1). The mushroom species were identified by Dr. Muhammad Muzammil Jahangir, Assistant Professor, Institute of Horticultural Sciences, University of Agriculture, Faisalabad. All the collected mushroom samples were brought to the Bioassay section of the Medicinal Biochemistry Lab, Department of Biochemistry, University of Agriculture, Faisalabad for further processing. The samples were shade dried, ground into a fine powder and one-half was tested for proximate composition while the $2^{\text {nd }}$ half for extract preparations in different solvents like methanol, ethyl acetate, and $n$-hexane for studying antioxidant potential and fatty acid profiling.

\section{Proximate analysis of selected mushrooms}

Proximate analysis of dried mushrooms was studied for moisture content, crude fat, crude fiber,

Table 1. Collection and classification of mushrooms.

\begin{tabular}{|c|l|l|l|}
\hline No. & Common Name & Botanical Name & Location \\
\hline 1 & Red-Cracked Bolete & Xerocomellus chrysenteron & Kesarian (Keran) \\
\hline 2 & Ganoderma & Ganoderma lucidum & Arlian (Behri Nullah) \\
\hline 3 & Mycena & Mycena vitilis & Bugna (Athmuqam) \\
\hline 4 & Velvet Shank & Flammulina velutipes & Shah kot (Athmuqam) \\
\hline 5 & Candy Cap & Lactarius rubidus & Kutton (Kundal Shahi) \\
\hline 6 & Short-Stemmed Russula & Russula brevipes & Seemari (Chillehana) \\
\hline 7 & Beechwood Sickener & Russula nobilis & Chita khata (Kundal Shahi) \\
\hline 8 & White Saddle & Helvella crispa & Ratti gali (Kundal Shahi) \\
\hline 9 & Woodland Fungus & Laccaria bicolor & Shahkot (Athmuqam) \\
\hline
\end{tabular}


total carbohydrates, crude protein, and ash contents via following methods.

\section{Moisture content}

The moisture content of mushroom samples was determined through the method described by Ayub et al. (13). Mushroom powder (2 g) was transferred into a pre-weighed crucible and placed at $120^{\circ} \mathrm{C}$ in thermostatic oven and weighed till constant weight. Moisture content was expressed as a percentage by weight of the mushroom sample.

\section{Estimation of crude fats}

Crude fats of selected mushroom powder samples were determined through the method proposed by Ayub et al. (13). For crude fat, the dried mushrooms powder was taken in cellulose thimble which was fixed in the extraction tube of Soxhlet apparatus and kept in a water bath. Water bath temperature was adjusted so that the constant stream of water falls on the extraction thimble. Extraction was carried out with petroleum at $40-60^{\circ} \mathrm{C}$ for $16 \mathrm{~h}$. After $16 \mathrm{~h}$ of extraction, the sample was removed from the thimble and added into a flask. Then it was dried by evaporating the solvent on a boiling water bath. After that extract was kept in a hot air oven at $105^{\circ} \mathrm{C}$ for $30 \mathrm{~min}$ and dried completely. The sample was cooled in a desiccator and weight of dried mushroom powder was documented. Percentage of crude fat was determined with the given formula:

Percentage crude fat $=$ Weight of fat sample in gram $\times 100 /$ Weight of sample

\section{Estimation of crude protein}

Crude protein was estimated using the Kjeldahl apparatus following the protocol of Ayub et al. (13). Percentage crude protein of mushroom was calculated by the following formula:

Crude protein $(\%)=6.25 \times$ Nitrogen $(\%)$

Fat-free mushroom samples of known weight were enclosed in filter paper (Whatman no. 1) and placed on Kjeldhal apparatus in digestion flask. Sulphuric acid $(10 \mathrm{~mL})$ and one gram of reaction catalyst $\left(\mathrm{SeO}_{2}, \mathrm{CuSO}_{4}\right.$ and $\mathrm{Na}_{2} \mathrm{SO}_{4}$ in the ratio of $1: 5: 10$ ) were added to facilitate the digestion of the sample. Flasks were placed on the Gallenkamp digestion apparatus for two hours until the reaction mixture turned into light green. The reaction mixture was cooled and added distilled water to make reaction volume up to $100 \mathrm{~mL}$ in a volumetric flask. $10 \mathrm{~mL}$ of aliquot was taken from a diluted solution, added with $10 \mathrm{~mL}$ of sodium hydroxide solution (45\%) and then placed on the Manhan distillation apparatus. It was then distilled into $2 \%$ boric acid
$(10 \mathrm{~mL})$ which contains few drops of methyl red indicator/bromocresol green and titrated against standardized $0.01 \mathrm{~N} \mathrm{HCl}$ to end point of grey colored to obtain nitrogen. The percentage crude protein in mushroom sample was calculated by the formula:

Crude protein $(\%)=(\mathrm{a}-\mathrm{b}) \times 0.01 \times 14.01 \times \mathrm{C}$

$$
\times 100 \times 6.25 / \mathrm{d} \times \mathrm{e}
$$

Where: $\mathrm{a}=$ Titration value of the digested mushroom sample, $\mathrm{b}=$ Titration value of the blank, $\mathrm{c}=$ Volume to which the digested sample was made with distilled water $(100 \mathrm{~mL}), \mathrm{d}=$ Sodium hydroxide volume used for distillation, $\mathrm{e}=\mathrm{Wt}$ of fat-free dried sample.

\section{Fatty acids profiling of mushrooms through GC- MS analysis \\ Extraction}

Mushroom samples $(200 \mathrm{mg})$ were taken and transferred into $12 \times 1.5 \mathrm{~cm}$ tube. Then $1 \mathrm{~mL}$ of absolute chloroform and $3 \mathrm{~mL}$ of methanolic $\mathrm{HCl}$ (5\%) prepared by mixing $10 \mathrm{~mL}$ of acetyl chloride with $100 \mathrm{~mL}$ of anhydrous methanol were slowly added into that tube. Tubes were vortex and heated for $1 \mathrm{~h}$ at $100^{\circ} \mathrm{C}$. After cooling to room temperature, $5 \mathrm{~mL}$ of $6 \%$ potassium carbonate and $4 \mathrm{~mL}$ of chloroform were added and again vortex for $30 \mathrm{sec}$ and centrifuged for $10 \mathrm{~min}$ at $25000 \mathrm{rpm}$. After centrifugation two separate layers were formed, the upper layer was removed and the lower layer was washed with chloroform $(4 \mathrm{~mL})$ to completely remove the organic compounds. It was dried with nitrogen and suspended in $n$-hexane $(2 \mathrm{~mL})$ and $0.88 \% \mathrm{KCl}(4$ $\mathrm{mL}$ ), again two layers were formed. The upper layer was removed and analyzed for GC-MS analysis (14).

\section{Instrumentation and chromatography}

The GC-MS model 6890 Hewlett-Packard (Wilmington, DE), which was equipped with electronic pneumatics control and automated liquid sampler (model 7683) was used for separation and detection of methyl esters of fatty acids. $2 \mu \mathrm{L}$ of sample fused with silica (WCOT) chemically bonded with capillary column (100 m long), (0.25- $\mu \mathrm{m}$ film thickness); ( $0.25 \mathrm{~mm}$ inside diameter), (0.39 $\mathrm{mm}$ outside diameter) was used for analysis. Helium ( $3 \mathrm{~mL}$ ) was used as a carrier gas. The temperature gradient $\left(70-250^{\circ} \mathrm{C}\right)$ was maintained. Temperature of the injector and detector was kept at $280^{\circ} \mathrm{C}$ and $300^{\circ} \mathrm{C}$, respectively. The GLC-63B, Nu-Check- Prep, and Elysian MN were utilized as reference standards for fatty acid detection through their retention time and quantification was done through Hewlett-Packard Chem (station data system). Fatty acids quantification on a dry matter basis was lauric, myristate, 
palmitic, palmitoleic, stearic, oleic, linoleic, $\alpha$-linolenic acid. The heptodecanoic acid $(0.4 \mathrm{mg} / \mathrm{mL}$ in hexane) was used as a reference standard (14).

\section{Preparation of mushroom extracts for biological activities}

For biological screening, dried mushroom powder was extracted with extraction solvents such as methanol, ethyl acetate, and $n$-hexane following the protocol of Guo, 2012 (15) with some modifications. Mushroom powder (100 g) was extracted with each solvent thrice. After filtration, the solvent was concentrated on a rotary evaporator and used for biological evaluation.

\section{Antioxidant potential of selected mushrooms extracts \\ Total phenolic contents (TPC) \\ TPC was determined through the Folin-Ciocal- teu (FC) method of Nandi et al. (16). $1 \mathrm{~mL}$ of mush- room extracts were mixed with $5 \mathrm{~mL}$ of $\mathrm{FC}$ reagent, $4 \mathrm{~mL}$ of sodium carbonate solution and the reaction mixture was incubated for $2 \mathrm{~h}$. After incubation, absorbance of the reaction mixture was noted at 765 $\mathrm{nm}$. The TPC in mushroom drawn outs as GAE was calculated from Gallic acid standard curve by fol- lowing formula:

$$
\mathrm{T}=\mathrm{C} \times \mathrm{V} / \mathrm{M}
$$

Where: $\mathrm{T}=$ Total phenolic contents in $\mathrm{mg}$ GAE/g mushroom extract, $\mathrm{C}=$ Gallic acid concentration as estimated from standard curve in $\mathrm{mg} / \mathrm{mL}, \mathrm{V}=$ Extract volume, $\mathrm{M}=$ Grams weight of mushroom extracts.

\section{Total flavonoids contents (TFC)}

TFC of mushroom extracts was assessed by following the protocol of Bendec et al. (17) with slight modifications. $0.5 \mathrm{~mL}$ of mushroom extracts were mixed with $1 \mathrm{~mL}$ of distilled water and $150 \mu \mathrm{L}$ of $5 \% \mathrm{NaNO}_{2}$ solution. The reaction mixture was incubated for $6 \mathrm{~min}$ at room temperature. After incubation, $150 \mu \mathrm{L}$ of $\mathrm{AlCl}_{3}(10 \%)$ was added and again incubated for $6 \mathrm{~min}$. After $6 \mathrm{~min}, 2 \mathrm{~mL}$ of $1 \mathrm{M}$ solution of $\mathrm{NaOH}$ was mixed with a reaction mixture and reaction volume was made up to $5 \mathrm{~mL}$ with distilled water and read at $510 \mathrm{~nm}$. TFC contents were expressed as catechin equivalent.

\section{DPPH scavenging assay}

The free radical scavenging activity of mushroom extracts was determined by following the DPPH inhibition procedure of Nowacka et al. (18). Mushroom extracts $(50 \mu \mathrm{L})$ were mixed with $0.004 \%$ solution of DPPH $(5 \mathrm{~mL})$ and the reaction mixture was kept in dark for $30 \mathrm{~min}$. After incubation, the absorbance of the reaction mixture was noted at $517 \mathrm{~nm}$ against a blank containing DPPH only. Percentage inhibition of DPPH radicals was calculated by the following formula given below. Vitamin $\mathrm{C}$ was used as a positive a control.

$$
\mathrm{I} \%=\left(\mathrm{A}_{\text {blank }}-\mathrm{A}_{\text {sample }} / \mathrm{A}_{\text {blank }}\right) \times 100
$$

\section{Statistical analysis}

The data obtained were entered into the Excel sheet and the Mean \pm SD was calculated. The statistical significance of the data was evaluated by applying one way ANOVA using SPSS version 22 (SPSS Inc, Chicago, IL, USA).

\section{RESULTS AND DISCUSSIONS}

In past decades, mushrooms have gained a lot of interest mostly in their consumption as food. Considering the nutraceutical and nutritional aspects of mushrooms, now research is being focused on investigating their proximate composition, antioxi-

Table 2. Proximate composition of studied mushrooms (\% DW).

\begin{tabular}{|c|l|c|c|c|c|c|c|}
\hline No. & Mushrooms & $\begin{array}{c}\text { CP } \\
(\%)\end{array}$ & $\begin{array}{c}\text { Crude Fat } \\
(\%)\end{array}$ & $\begin{array}{c}\text { Fiber } \\
(\%)\end{array}$ & $\begin{array}{c}\text { Carbohydrate } \\
(\%)\end{array}$ & $\begin{array}{c}\text { Ash } \\
(\%)\end{array}$ & $\begin{array}{c}\text { Energy } \\
\text { Kcal/100 g }\end{array}$ \\
\hline 1 & X. chrysenteron & $22.61 \pm 0.2$ & $0.78 \pm 0.1$ & $9.38 \pm 03$ & $70.62 \pm 0.3$ & $5.99 \pm 0.2$ & $374.3 \pm 0.2$ \\
\hline 2 & G. lucidum & $21.14 \pm 0.4$ & $2.02 \pm 0.2$ & $6.11 \pm 0.2$ & $69.86 \pm 0.2$ & $7.02 \pm 0.4$ & $378.5 \pm 0.2$ \\
\hline 3 & M. vitilis & $18.80 \pm 0.2$ & $2.01 \pm 0.1$ & $7.10 \pm 0.5$ & $76.50 \pm 0.2$ & $7.51 \pm 0.2$ & $386.3 \pm 0.2$ \\
\hline 4 & F. velutipes & $24.12 \pm 0.3$ & $0.67 \pm 0.2$ & $9.33 \pm 0.3$ & $65.34 \pm 0.3$ & $9.09 \pm 0.4$ & $363.8 \pm 0.3$ \\
\hline 5 & L. rubidus & $15.04 \pm 0.1$ & $0.53 \pm 0.3$ & $54.12 \pm 0.2$ & $82.47 \pm 0.2$ & $2.01 \pm 0.2$ & $394.5 \pm 0.2$ \\
\hline 6 & R. brevipes & $30.15 \pm 0.4$ & $5.08 \pm 0.3$ & $46.3 \pm 0.4$ & $66.54 \pm 0.4$ & $9.14 \pm 0.5$ & $354.80 \pm 0.4$ \\
\hline 7 & R. nobilis & $25.51 \pm 0.9$ & $2.75 \pm 0.4$ & $44.12 \pm 0.7$ & $82.47 \pm 0.3$ & $2.1 \pm 0.3$ & $368.41 \pm 0.4$ \\
\hline 8 & H. crispa & $27.15 \pm 0.4$ & $6.01 \pm 0.3$ & $43.2 \pm 0.3$ & $65.66 \pm 0.3$ & $7.03 \pm 0.5$ & $394.30 \pm 0.4$ \\
\hline 9 & L. bicolor & $14.12 \pm 0.3$ & $1.67 \pm 0.2$ & $8.33 \pm 0.3$ & $55.34 \pm 0.3$ & $6.09 \pm 0.4$ & $163.8 \pm 0.3$ \\
\hline
\end{tabular}


Table 3. Total phenolic contents $(\mathrm{mg} \mathrm{GAE} / \mathrm{mL})$ in different extracts of mushrooms.

\begin{tabular}{|c|l|c|c|c|}
\hline No. & Mushroom & Methanol & Ethyl acetate & n-Hexane \\
\hline 1 & X. chrysenteron & $530.4 \pm 4.012$ & $280.4 \pm 2.062$ & $10.4 \pm 2.003$ \\
\hline 2 & G. lucidum & $371.8 \pm 3.120$ & $316.4 \pm 3.192$ & $16.4 \pm 2.754$ \\
\hline 3 & M. vitilis & $330.4 \pm 3.225$ & $180.4 \pm 2.008$ & $15.2 \pm 1.034$ \\
\hline 4 & F. velutipes & $380.4 \pm 3.011$ & $160.4 \pm 2.005$ & $18.4 \pm 1.983$ \\
\hline 5 & L. rubidus & $160.4 \pm 2.002$ & $160.4 \pm 2.003$ & $8.4 \pm 1.005$ \\
\hline 6 & R. brevipes & $460.4 \pm 4.002$ & $130.4 \pm 1.984$ & $5.4 \pm 1.043$ \\
\hline 7 & R. nobilis & $230.4 \pm 2.154$ & $156.4 \pm 2.005$ & $18 \pm 1.035$ \\
\hline 8 & H. crispa & $380.4 \pm 3.084$ & $177.6 \pm 1.723$ & $17.6 \pm 1.041$ \\
\hline 9 & L. bicolor & $160.4 \pm 2.162$ & $133.8 \pm 1.820$ & $13.8 \pm 1.027$ \\
\hline
\end{tabular}

Table 4. Total flavonoid contents $(\mathrm{mg} \mathrm{CE} / \mathrm{mL})$ in different mushrooms extracts.

\begin{tabular}{|c|l|c|c|c|}
\hline No. & Mushroomspecies & Methanol & Ethyl acetate & n-Hexane \\
\hline 1 & X. chrysenteron & $76.71 \pm 3.021$ & $68.364 \pm 3.002$ & $4.56 \pm 3.902$ \\
\hline 2 & G. lucidum & $23.28 \pm 1.043$ & $20.364 \pm 1.042$ & $7.78 \pm 1.007$ \\
\hline 3 & M. vitilis & $92.5 \pm 3.923$ & $74.453 \pm 3.912$ & $9.76 \pm 3.061$ \\
\hline 4 & F. velutipes & $53.55 \pm 2.973$ & $49.243 \pm 2.063$ & $7.33 \pm 2.834$ \\
\hline 5 & L. rubidus & $37.5 \pm 1.032$ & $29.464 \pm 1.004$ & $9.98 \pm 1.006$ \\
\hline 6 & R. brevipes & $86.18 \pm 3.052$ & $74.354 \pm 3.001$ & $3.76 \pm 2.071$ \\
\hline 7 & R. nobilis & $53.81 \pm 2.032$ & $25.354 \pm 2.912$ & $9.65 \pm 2.005$ \\
\hline 8 & H. crispa & $88.55 \pm 3.041$ & $68.638 \pm 3.004$ & $3.87 \pm 3.881$ \\
\hline 9 & L. bicolor & $49.07 \pm 2.053$ & $42.465 \pm 2.038$ & $10.56 \pm 3.069$ \\
\hline
\end{tabular}

dant activities, GC-MS analysis for fatty acid profiling.

\section{Proximate composition of selected mushrooms}

Before extraction, the dried mushroom samples were explored for their proximate composition. Results of the proximate analysis were given in Table 2.

The results demonstrated that crude protein contents of mushrooms were in the range of 10 to $30 \%$. Highest protein contents $(30 \%)$ have been recorded in $R$. brevipes followed by $H$. crispa $(27 \%)$, $R$. nobilis $(25 \%)$ and $F$. velutipes $(24 \%)$. Sabir et al. (19) in their study determined the protein contents in different mushrooms collected from Azad Kashmir forests and their protein contents were in the range of $15.56-30.65 \%$. Wang et al. (7) also determined protein contents (12.0-29.3\%) of different mushrooms collected from China. Barros et al. (9) reported protein contents in C. cibarius $(54 \%)$ and $A$. caesaria $(59 \%)$ which are more than protein contents of A. caesaria $(34.77 \%)$ and C. cibarius $(21.57 \%)$ reported by Ouzouni et al. (20).
Crude fat in different mushrooms was recorded in the range of 0.53 to $5.08 \%$ (Table 2). Fat contents are usually low (1.0\% to $6.7 \%$ ) in different mushrooms of China as reported by Wang et al. (7). Ouzouni et al. (20) also determined the crude fat contents in A. mellea (2.10\%) and H. russula (6.0\%). Our results also showed a positive correlation with the results reported by Beluhan and Ranogajec (2011) (21) (1.34-6.45 g/100 g fat) in 10 Croatian mushrooms. Heleno et al. (22) also reported fat contents $(0.36-2.63 \mathrm{~g} / 100 \mathrm{~g})$ in different mushrooms which are less than our results.

Fiber contents were significant in L. rubidus and were lowest in G. lucidum (6\%) (Table 2). Sabir et al. (19) reported crude fiber of 10 different mushrooms from Azad Jammu and Kashmir in the range of $5.43-17.44 \%$. The results of the study confirmed a substantial amount of fiber which are recognized as hypocholesterolemic and anti-tumorigenic agent. This entails that mushrooms hold extraordinary attraction and possibly suggested for people suffering from cholesterol-related diseases. 


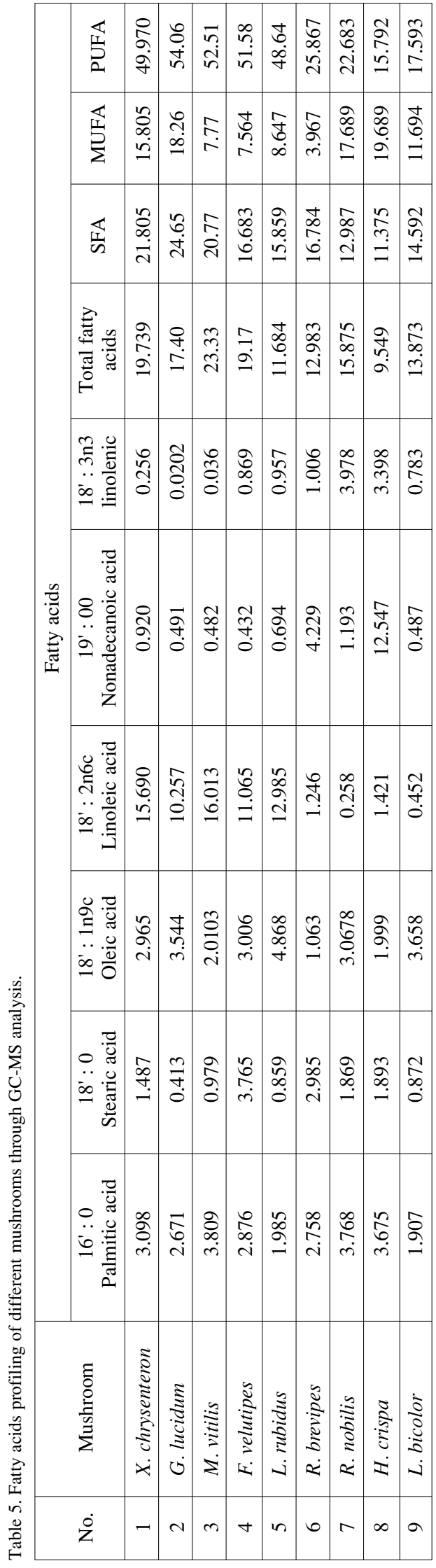

Total carbohydrates varied in the range of 52$92 \%$ on dry weight basis with the highest carbohydrate contents in L. rubidus and $R$. nobilis while lowest carbohydrates in L. mitissimus (52\%).

Calorie values of mushrooms in the present study were found to be in the range of 394-163 $\mathrm{Kcal} / 100 \mathrm{~g}$. Calorie value was found to be highest (394 kcal/100 g) in L. rubidus and lowest (363.5 $\mathrm{Kcal} / 100 \mathrm{~g}$ ) in L. bicolor. Total ash was maximum in the $R$. brevipes $(9.14 \%)$.

\section{Antioxidant potential of selected wild mushrooms}

Medicinal properties of mushrooms are well known because they contain different polyphenolic compounds having the ability to scavenge free radicals by single electron transfer. The role of free radicals is connected with the development of various health problems, including coronary heart disease, cancer, and other infectious diseases, neuronal disorders, diabetes, and arthritis. So, dietary antioxidants are believed to maintain good health as well as in the prevention of various diseases (23).

\section{Total phenolic contents}

The total phenolic contents of mushroom extracts were analyzed by the Folin-Ciocalteau method and results were presented as mg Gallic acid equivalent per $\mathrm{mL}$ of mushroom fractions. Among the considered species, $X$. chrysenteron showed significant total phenolic contents. Methanolic fraction of all the studied mushrooms showed the highest phenolic contents as it is a preferable solvent for the extraction of phenolics. Our study showed that methanol may be a useful solvent for the extraction of antioxidants from a number of mushroom species after applying different partition solvents. The TPC in X. chrysenteron, G. lucidum, Mycena vitilis, $F$. velutipes, $L$. rubidus, $R$. brevipes, $R$. nobilis, H. crispa, L. bicolor are 530.4, 371.8, 330.4, 380.4, 160.4, 460.4, 230.4, 380.4, 160.4 mg GAE/mL. The $n$-hexane and ethyl acetate fractions were weaker radical scavengers than polar methanolic fractions; this is in agreement with many previously published results showing that polar solvents extract more antioxidants from botanicals than lower polarity solvents (24). Thus the TPC values in all the fractions were present in following decreasing order methanol $>$ ethyl acetate $>n$ hexane. The total phenolic contents in a methanolic fraction of mushroom extracts were in the range of 130.4-614.4, in ethyl acetate 83.8-316.4 and in the case of $n$-hexane it is in the range of 8.2-116.4 (Table 3).

\section{Total flavonoid contents}

In order to attain more information concerning the nature of phenolic substances in mushrooms 


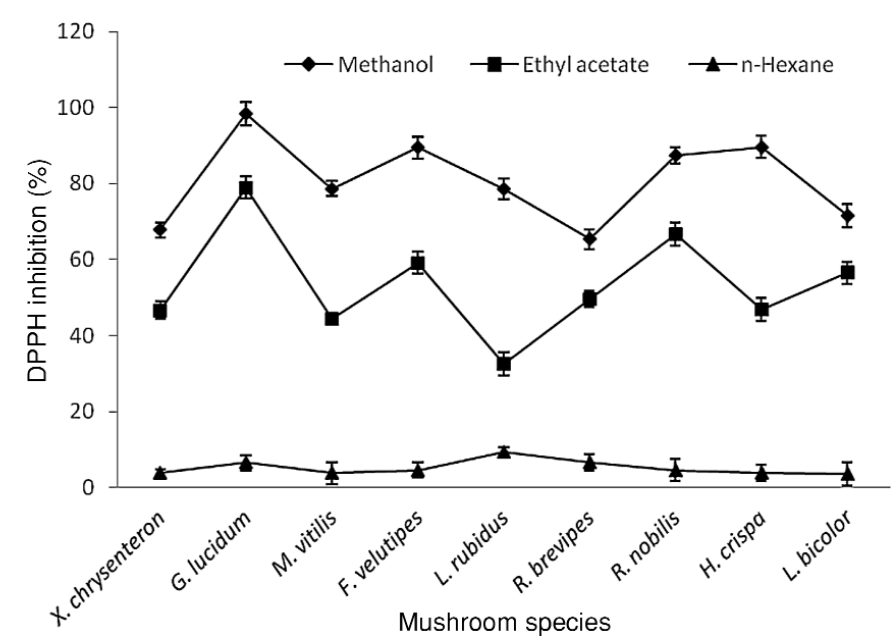

Figure 1. Percentage DPPH inhibition potential of different extracts of mushrooms.
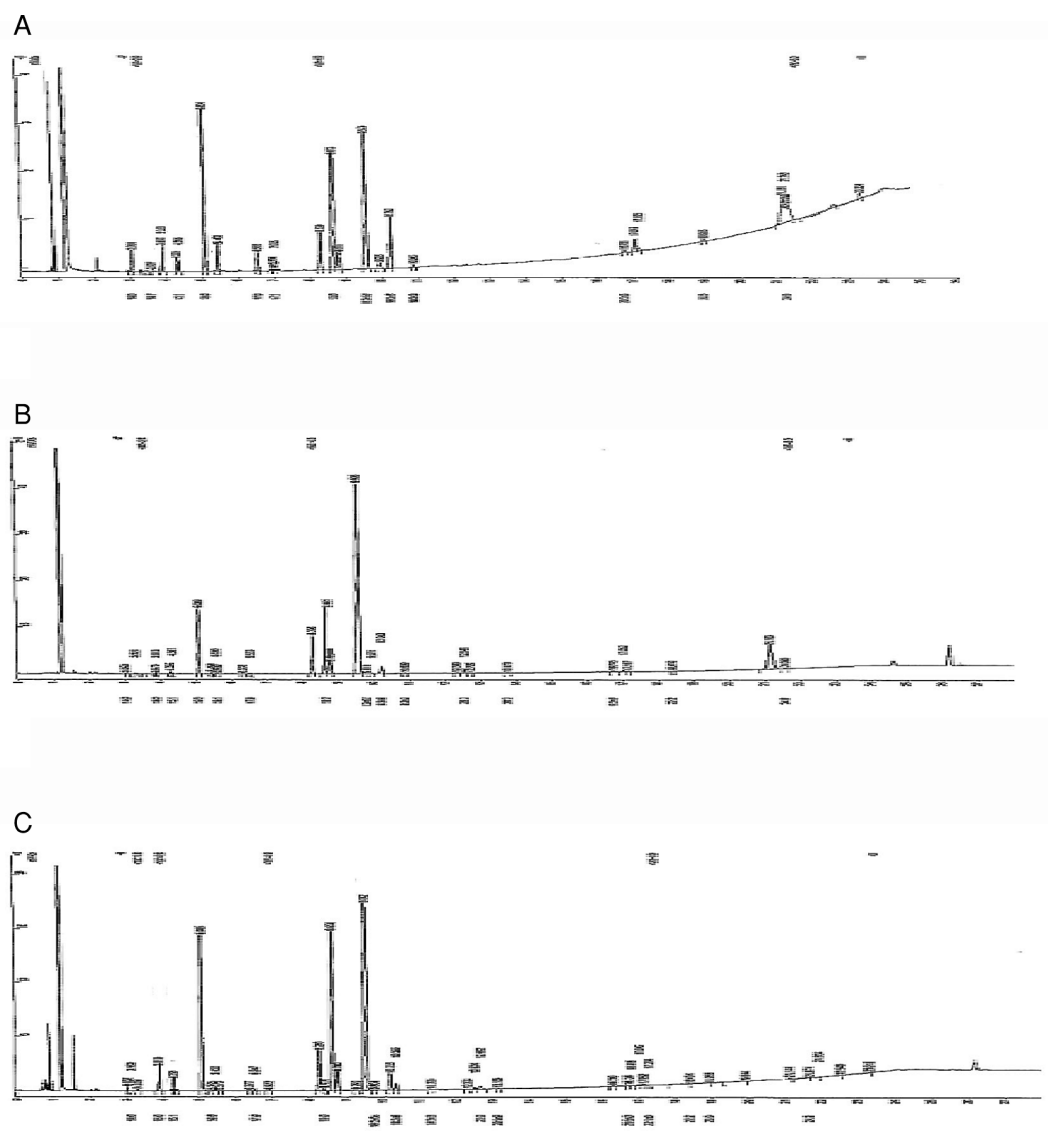

Figure 2. GC-MS profile of fatty acids of (A) M. vitilis (B) R. nobilis and (C) L. bicolor:

species, total flavonoid contents were also calculated. The results were expressed as catechin equivalent per $\mathrm{mL}$ of mushrooms fraction. Total flavonoids contents of X. chrysenteron, G.a lucidum, M. vitilis, $F$. velutipes, L. rubidus, $R$. brevipes, $R$. nobilis,
H. crispa, L. bicolor, in methanolic extracts are 23.28, 92.5, 53.55, 37.5, 86.18, 53.81, 52.5, 49.07, 86.31 , respectively. TFC contents were also higher in methanolic extracts followed by ethyl acetate and hexane as given in Table 4. 


\section{DPPH inhibition potential of Mushroom}

Free radical scavenging is one of the methods by which antioxidants inhibit lipid oxidation. The radical scavenging ability of mushrooms fraction was tested next to DPPH, a stable free radical of violet color that usually fades or vanish when an antioxidant is there in the medium with characteristic fascination at $515 \mathrm{~nm}$. As antioxidant compounds give protons to these radicals, the absorbance of reaction mixture decreases. This decrease in absorbance is used to determine radical scavenging potential of extracts (25). The DPPH scavenging activity of mushrooms extracts is illustrated in Figure 1. Among all fractions, methanolic fractions of all the studied mushrooms showed the highest inhibition of DPPH. The percentage inhibition of $X$. chrysenteron, G. lucidum, M. vitilis, F. velutipes, L. rubidus, $R$. brevipes, $R$. nobilis, $H$. crispa, and L. bicolor is 67.87, 98.43, 78.69, 89.44, 78.54, 65.33, 87.44, 89.65 , and 71.43 , respectively.

\section{Fatty acid profiling of mushrooms by GC-MS analysis}

Lipids are the least considered components of mushrooms because their overall content in different species is around 6-8\% of their dry weight, and one of the best advantages of mushrooms is their low lipids contents. The information about the lipid composition as primary metabolites is of huge attention because it adds to the common nutritional worth and may give a special place to mushrooms in global life forms. Collected mushrooms were also evaluated for their fatty acids composition (26). Results of fatty acids analysis of mushrooms including saturated fatty acids (SFA), total fatty acids, polyunsaturated fatty acids and monounsaturated fatty acids (MUFA) were presented in Table 5. GC-MS spectra of fatty acids of mushroom species $M$. vitilis, $R$. nobilis and $L$. bicolor are shown in Figure 2.

The results showed different fatty acids like nonadecanoic acid (C19-0), oleic (18': 1n9c), linoleic (18': 2n6c), palmitic acids (C16:0), linolenic $\left(18^{\prime}: 3 \mathrm{n} 3\right)$ and stearic acid (C18:0) were the main fatty acids investigated in the mushrooms. The highest concentration of stearic acid was present in F. velutipes, L. rubidus contains the highest amount of oleic acid. The polyunsaturated fatty acids were more prevalent over the saturated fatty acids. X. chrysenteron, G. lucidum, M. vitilis, F. velutipes, and L. rubidus contain more amount of polyunsaturated fatty acids as compared to other mushrooms. Total fatty acids were the highest in $M$. vitilis followed by $X$. chrysenteron and $F$. velutipes.

\section{CONCLUSION}

It was concluded that all mushrooms are a good source of proteins, carbohydrates, crude fiber, while fat contents are low in most of the mushrooms. It was also observed that mushrooms are the potential source of antioxidants. Analysis of fatty acid through GC/MS explained that oleic, linoleic, palmitic, linolenic, stearic and nonadecanoic acids were identified in the selected mushrooms. Unsaturated fatty acids (UFA) preponderated over the saturated fatty acids in all the studied mushrooms.

\section{Acknowledgment}

We are highly thankful to the Higher Education Commission of Pakistan for providing funding under NRPU project Grant No. 3224 and the costs of all the experimental and other research-related activities are covered under this project.

\section{Conflict of interests}

The authors declare no conflict of interest.

\section{REFERENCES}

1. Mukhopadhyay R., Guha A.K.: LWT-Food Sci. Technol. 61, 339 (2015).

2. Mosisa Z.H., Kebede A., Preetha V.V.: Int. J. Adv. Res. 3. 522 (2015)

3. Babu P.D., Subhasree R.: Adv. Biol. Res. 4, 207 (2010).

4. Petkovšek S.A.S., Pokorny B.: Sci. Total Environ. 443, 944 (2013.

5. Sun Y.S.: Carbohyd. Polym. 85, 4902011.

6. Xing Z., Zhao X.: in Global Safety of Fresh Produce. Hoorfar J. Ed., pp. 401-408, Woodhead Publishing Limited 2014

7. Wang X-M., Zhang J., Wu L-H., Zhao Y-L., Li T., Li J-Q., et al.: Food Chem. 151, 279 (2014).

8. Kishwar S., Shinwari Z., Farida I.: Pakistan J. Agri. Res. 20, 88 (2007).

9. Barros L., Correia D.M., Ferreira I.C., Baptista P., Santos-Buelga C.: Food Chem. 110, 1046 (2008).

10. Ren L., Hemar Y., Perera C.O., Lewis G., Krissansen G.W., Buchanan P.K.: Bioact. Carbohydr. Dietary Fibre 3, 41 (2014).

11. Egwin E., Elem R., Egwuche R.: Am. J. Food Nutr. 1, 89 (2011).

12. Unekwu H.R., Audu J.A., Makun M.H., Chidi E.E.: Asian Pac. J. Trop. Dis. 4, S153 (2014). 
13. Ayub V., Ojobe T., Ayuba S.: Journal of Medicinal Plants Research. 5, 2952 (2011).

14. Clapham W.M., Foster J.G., Neel J.P., Fedders J.M.: J. Agr. Food Chem. 53, 10068 (2005).

15. Guo Y-J., Deng G-F., Xu X-R., Wu S., Li S., et al.: Food Funct. 3, 1195 (2012).

16. Nandi A.K., Samanta S., Maity S., Sen I.K., Khatua S., et al.: Carbohyd. Polym. 99, 774 (2014).

17. Benedec D., Vlase L., Hanganu D., Oniga I.: Dig. J. Nanomater. Bios. 7, 1263 (2012).

18. Nowacka N., Nowak R., Drozd M., Olech M., Los R., Malm A.: PLoS One 10, e0140355 (2015).

19. Sabir S.M., Hayat I., Hussain I., Gardezi S.R.A.: Pak. J. Plant Pathol. 2, 97 (2003).
20. Ouzouni P.K., Petridis D., Koller W-D., Riganakos K.A.: Food Chem. 115, 1575 (2009).

21. Beluhan S., Ranogajec A.: Food Chem. 124, 10762011.

22. Heleno S.A., Barros L., Sousa M.J., Martins A., Ferreira I.C.: Microchem. J. 93, 195 (2009).

23. Smolskaitė L., Venskutonis P.R., Talou T.: LWT-Food Sci. Technol. 60, 462 (2015).

24. Brahmi F., Mechri B., Dabbou S., Dhibi M., Hammami M.: Ind. Crop. Prod. 38, 146 (2012).

25. Woldegiorgis A.Z., Abate D., Haki G.D., Ziegler G.R.: Food Chem. 157, 30 (2014).

6. Marekov I., Momchilova S., Grung B., Nikolova-Damyanova B.: J. Chromatogr. B 910, 54 (2012).

C 2020 by Polish Pharmaceutical Society. This is an open access article under the CC BY NC license 